\title{
A Comparative Analysis of Power Consumption in Conventional and Differential - Less Drive for Electric Vehicle
}

\author{
Abhijeet Dhulekar ( $\sim$ dhulekarabhijeet@gmail.com ) \\ PR Pote Patil Education and Welfare Trust's College of Engineering and Management \\ https://orcid.org/0000-0001-8915-7300
}

\section{Pankaj Ardak}

Dr Rajendra Gode Institute of Technology \& Research

\section{Original Article}

Keywords: Driver model Vehicle transmission, Energy simulation analysis, Electronic variable transmission, planetary losses, Electric Vehicles, Differential losses

Posted Date: September 7th, 2021

DOI: https://doi.org/10.21203/rs.3.rs-876094/v1

License: (a) (i) This work is licensed under a Creative Commons Attribution 4.0 International License. Read Full License 


\title{
Title - A Comparative Analysis of Power Consumption in Conventional and Differential - Less Drive for Electric Vehicle
}

\author{
Abhijeet Dhulekar ${ }^{a}$, Pankaj Ardak ${ }^{b}$ \\ P. R. Pote College of Engineering And Management Amravati, Department of Mechanical Engineering, Amravati, India. \\ Dr. Rajendra Gode Institude of Technology \& Research, Department of Mechanical Engineering, Amravati, India.
}

Corresponding Author Name \& Mail: Abhijeet Dhulekar [ dhulekarabhijeet@gmai.com ]

\begin{abstract}
The general design of the methodology of the transmission system is usually used to give efficient power to the driven wheel, such as usually used differential to differentiate speed and motion of the wheel. In this paper; we analyze methods of motion control and power transmission variation for an electric vehicle (EV) with two independently driven in-wheel motors and conventional differential used EV. Compares the power transmission ratio of two different configurations drives energy conversion differential and epicyclic gears train analysis. This investigation gives an orderly examination of compendium an electrical vehicle is driven by transmissions system journals published and about different losses through mechanical differential system transmission and how they affect on torque. These studies present a comprehensive convergent study report of power Variation and torque transmission with simulation result distinction in differential and differential-less EV's by compendium studies and show some comparative results. After a compendium study author finds few losses in differentials such as Pocketing power losses, WPL, drag mishap, friction, and different slip in gears. We have mention different factors also affect drive trains and illustrate the main reason to generate losses during transmission. In addition, we have explained this through simulation.
\end{abstract}

Keywords : Driver model Vehicle transmission, Energy simulation analysis, Electronic variable transmission, planetary losses, Electric Vehicles, Differential losses.

\begin{tabular}{ll}
\multicolumn{2}{l}{ Abbreviations } \\
ACC & Adaptive cruise control \\
CPA & Critical path analysis \\
DOF & Degree of freedom \\
P & Power Consumption (Watts) \\
N & Speed of Rotation (rpm) \\
T & Torque (N-m) \\
FTE & Total Tractive Effort \\
FG & Gradient force \\
Tw & Torque On Driving Axel \\
FAA & Angular Acceleration \\
FLA & Linear acceleration force \\
P & Power (watts) \\
S & Speed (rpm) \\
E & Energy (joule) \\
T & Time (sec) \\
FAD & Aerodynamic Drag Force (N) \\
$\rho$ & Density of Air \\
CD & Aerodynamic Drag Coefficient \\
V & Velocity of Vehicle \\
a & Frontal Area Of Vehicle \\
V air & Opposing Air Velocity
\end{tabular}

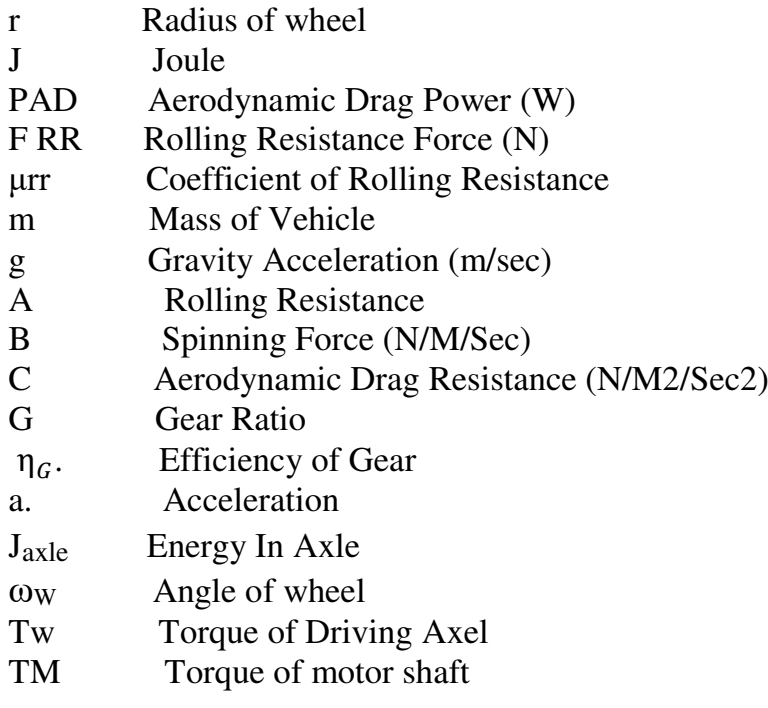

\section{Introduction}

Electric vehicles (EV's) extent the possibility to substantially diminish toxics emissions from the automobile and some hybrid electric vehicles with an 
extra feature of regenerative energy generation system such as alternator of the economy transportation. It will be a sustainable future with an electric vehicle is broadly considered as a reasonable technique for lessening oil reliance and ecological effects of street transportation. In 1834, the first non-rechargeable battery-operated EV was built by Thomas Davenport. In 1900 among 4200 automobiles sold in the USA, 38\% were EV $22 \%$ were IC electric vehicles and $40 \%$ were steam powder vehicles. In a generally not so distant future, we should supplant the exemplary internal combustion engine (ICE) with electric-driven invehicle. This change will be finished by the middle of the road stage, i.e. by the increment of the electric vehicles (EV) and hybrid electric vehicles (HEV).[51] Usually, typical electric-powered driven devices are utilized in EV and HEV also even in bikes. Nowadays, that is induction (IM) and permanent-magnet synchronous motors (PMSM). The two effective problems caused by internal combustion engine vehicles, energy scarcity, and environmental pollution, have become public attention already. Measures are pointing to this exigency, and one of the principal focal points of current research and flow innovative work patterns in reasonable car innovation is on advancing completely electric vehicles. [17]

The basic aim of this analysis is to review and compendium kinds of literature that show the intensive merits of various power transmissions systems of electric vehicles and such as with the importance of the integration of affordable Electrical vehicles consider with two different drivetrain modes to drive rear wheel of the vehicle electrical system. [52] Laterally conventional EV's used normal drivetrain as the IC engine vehicles a motor shaft coupled with a different type of propulsion system used is also deciding factors in some system gears and another gearless, they may use differential or not it can be as same as motors some electric vehicle used single or multi motors so depending on the type of EV. This design of $\mathrm{EV}$ has to do the same for all types of configuration. The focus of the current analysis, modeling the transmission mechanisms and find the effect on power transmission performance in the LDV transport era. And designing a new significant drive and control system befall of to enhance precision and to provide an effective easier way to control the electric vehicles. [53]

\subsection{Benefits Of Using Electric Vehicle}

The global population, with current trends, may surge from 6 billion to 10 billion by 2050 . Vehicles in use may increase from 7000 million in 2000 to 2.5 billion by 2050 . If all the vehicles are ICEV's, then all cities have been canopy with smog with noxious air pollution. Air research board reports (2011),[51] around 9000 people die per year due to fine particle matter in California. One of the assurance solutions is sustainable transport it means free from greenhouse gases vehicle promoting of public transport. There are various types of gases that are emitted from IC engine vehicles such as NOx, $\mathrm{CH} 2$, Sox, particulate matter, and volatile organic components this makes smoke and pollution. When those gases enter the body they affect to heart, lungs, eye. This particulate matter is cancerous in nature. $\mathrm{CO}, \mathrm{CO} 2$, NOx are greenhouse gases due to the presence of these gases the infrared radiation is trapped on the ozone layer and causes the greenhouse effect [47] as a consequence climate change and global warming happen. An electric vehicle is a zeroemission vehicle that is safe for human society. [61] EV has the advantage of a higher fuel economy than an IC engine vehicle. But the much more expensive due to initial battery cost and replacement after a few years. Advance battery electric vehicles having less maintenance and more reliability can recover energy during braking. It is less noisy and Electroniccontinuously variable transmission possible by the control unit.

\subsection{Differential System and Different Losses}

In an automobile, a differential framework, which showed up in Figure 1 involves information, the main turning shaft, and a group of gears system, which are connected to the two drive wheels; in any case, the revolution of the drive wheels is coupled by their associate shaft, and in contact with the street. the differential is the crucial structure of the Vehicle traction. Under average conditions, also with little tire slip, the proportion of the velocities of the two driving wheels are described by the proportion of the radii around which the two tires are rotating although the unidirectional or redirection, which in this way is constrained by the track-width of the vehicle (the division between the driving wheels) clear of the rotation. The differential framework assists the cars wheeled to alternate at corners by pivoting external wheels quicker than the inner wheel and turn the vehicle in circumscribe space. [45] As a basic when the cars take turns; forced the wheel that is going outside of the turning twist quicker than the inner wheel. Extending the mileage isn't the principal bit of leeway of growing force efficiency or plummets losses. Gears friction jot lubricated lead to increase temperatures. [57] Lower heat generation to fewer power losses compares to the differential casing, which generates problematics contact fatigue also scraping execution of the devices and directing. Where two basic strategies for power losses are rolling friction related to identified with the advancement of an Elasto Hydrodynamic Lubrication (EHL) film in the gear teeth, in addition, sliding friction-related with joined sliding-rolling speeds, ordinary powers, contact bends, and surface roughness differential mainly used bevel gears with adaptive heavyweight and certainly used under the high pressure and high viscous 
lubricant fluid tends to generated heavy power decrements. [6] On the other hand, loss of power incidents in gears is identified with the correspondences of the gears besiege with highvelocity fluid around them. Two essential sections of gears turn influence losses are (1) Drag mishaps identified with the resistive force of the oil or velocity of air (or an oil-air mix) alongside the side faces and edge of gears, and (2) Pocketing power losses related with the pumping of the fluid medium from pockets framed into adjoining teeth of a gears network interface. [69] Every piece of power setback is identified with certain working conditions. Gears friction losses are substantially vital at high-load, Low-speed conditions losses occur when the fluid film-formed at the interaction Interfaces in teeth is the minimum acceptable, makes huge friction. [6]

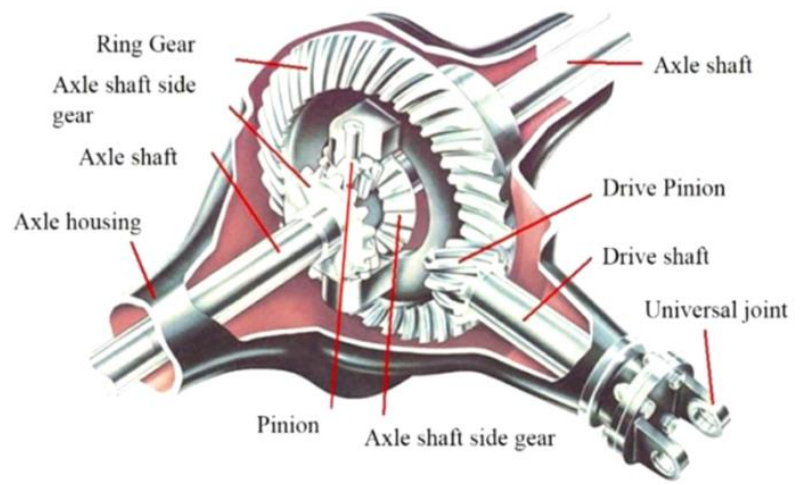

Fig. 1 Differential Gear System Assembly

\section{Literature Review}

EV configurations get parted between hybrid EV's and purpose-built EV's. Generally, hybrid EV's design used in past trends with heavyweight and loss of flexibility, etc.[1] but such all modern EV'S moved toward purpose-built more reliable configurations having new design structure frame.[4] Because of its attention properties of possibly high efficiency and creating no toxins, the fuel cell system is viewed as a perfect force source for vehicles EV's is more convenient than the IC engine vehicle because the power flow from one system to multiple is done mechanically with differential as well some EV's also referred to driveline attached with differential but In modern modified EV's application unitize direct motor drive or fixed geared driven system power transmission normally is done by a shaft which is very flexible and it allows the distribution of a different component of EV's throughout the vehicle with the help of field-oriented control (FOC) method is mostly utilized in electric vehicles as a speed controller[10], so that power transmission rate is high and loss of power responsible to friction is decreased attributable direct implementation of force during a wheel from the motor. Certainly, the IC engine has an unbelievable amount of losses in numerous components of transmission mechanism gears, uncertain, in differential on account of equipment associate degreed lubrication placed to position to minimize friction wherever the 2 essential strategies of intensity losses are rolling friction-related with engagement of an ELASTO fluid mechanics Lubrication (EHL) film between meshing teeth and contact curvatures, slippery friction-related with joined sliding-rolling velocities, surface roughness, and traditional forces. [5]

Additionally, turn power losses in gears are related to the cooperation of the gears contraption bodies with liquid medium around them. Two principal parts of mechanical assembly turn power losses are (1) Drag losses related to the beating of the oil or wind time of air (or an oil-air mix) close by the side faces and edge of gears, and (2) Pocketing losses identified with the siphoning of the liquid medium from pockets generate between close-by teeth at the gear organize interface. Each section of intensity setback is related to certain working conditions. Mechanical losses are commonly immense at highload, low-speed conditions when the liquid film encircled at the contact interfaces is the least extraordinary, causing basic erosion. [5] In prior years engines control issues. As opposed to the conventional vehicles dependent on inward ignition motors with mechanical differential, electric engines give the likelihood to autonomously control the driving/brake force of each engine wheel [17].

The multi-motor according to requirement differentiates speed in between two rear wheels so vehicle replaces and take a place of a differential system used to understand as standard EV's system, Expectation, and comprehension of the transmission loss within the differential system is vital because it provides the simplest way to create the influence transmission proficiency. Also, it provides experiences to enhance lubrication techniques, gear profiles, and equipment lodgings. [5] The multi-motor electric vehicles (EV's) a modern structure of chassis rotates without any slip and wear, tears of the tire at any condition. [38] New advanced EV's use the widest range of motors dc, synchronous motor, permanent magnet motor, induction motors, and BLDC motors [11, 12, and 13]. During analyzing previously published papers we found some conventional losses in power due to mechanical transmission in various systems direct motor is a more flexible method instead of a differential system. The EVs that we tend to contemplate are given of dual induction motors, gave by Associate in Nursing electrical converter, and gears. The idea we tend to propose is that the overall strength of the system might be optimized by exploiting the degree of freedom (DOF) given by the gear. Indeed, the gear contains a DOF we can categorize with the intention of the 
selection of the rpm of the combined motors, for each value of the speed required by the vehicle.[40][41]

\subsection{Implementation of multi motor drivetrain in EV's}

The graph fig. 2 ratio show used of a pure electric vehicle is more reliable for the society they mostly preferred pure electric motor the driven system instead of conventional hybrid this paper show flexibility of electric motors by comparing with losses of the differential system some accentuate fact of electric driveline configuration makes these more advantageous than another configuration. The drive framework is flexible and can be arranged for practically a wide range of EV's including power storage systems, plug-in hybrid, autonomous hybrid, and fuel cells. An electric motor directly introduce into a wheel with a planetary gear system take a place of IC engine and eliminate the related transmission and driveline parts, including propeller shaft, differential gears, the universal joints, and driveshaft. [15]

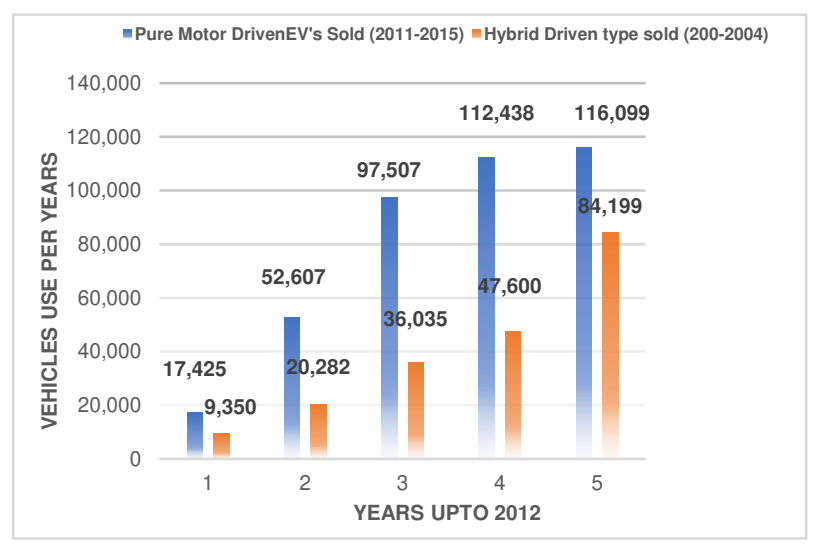

Fig.2 Graph on Usage of Multi Motor Drive Configuration From Past

\section{Drivetrain Systems Configuration}

Normal electric vehicles are moved by an internal combustion engine (ICE) and in this way they are likewise named internal combustion engine vehicles (ICEV's). This vehicle is known as an electric vehicle $(\mathrm{EV})$ if several electric motors are used to drive the wheels of a vehicle. Likewise, the vehicle is called the hybrid electric vehicle (HEV) if both an electric engine and ICE incite the wheels of a vehicle. [1] The differential is a very paramount mechanical device in an automobile that is used to create a differential in the speed of the front wheel such that it allows to turning operation without any discomfort to the operator without losing any control. There are namely three types that have been made in EV's system 1) conventional or normal type drives 2) EV with fixed geared and no clutch 3) EV configuration fixed geared coupled with driving axle.

\subsection{Conventional type with longitudinal front wheel drives}

Electric vehicle drivetrain system, which has been used in conventional vehicles and future of economical humanoid society, the conventional ICE vehicle is changed by a single rated electric motor, and the rest of the mechanical assembly is the same, as shown in Fig. 10. This design doesn't change the runof-the-mill structure of the drivetrain framework in ICEV's and thus is executed without any problem. Fig. 3 (a) present conventional torque and speed graph that will adhere to study analysis The requirement of the motor is it should work at full speed with the capacity of delivering full torque it doesn't need to operate in variable speed operation because that is done by variable gear system utilizing a clutch system, so this system is very easier to build in the small rated car. The motor that can be used conventional motor doesn't have to be design or EV application conventional motor [1]

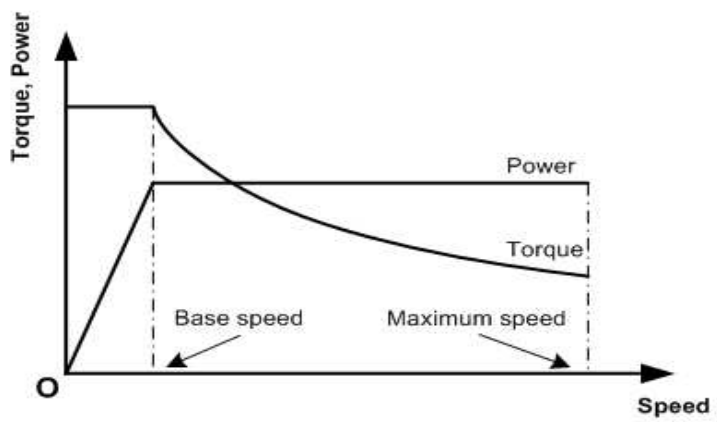

(a)

Vehicle execution, for the most part, incorporates increasing speed execution, assessed when utilize to accelerate the vehicle from 0 speed to a given acceleration (beginning acceleration), or from iota speed to a given quick (passing limit), level limit, evaluated by the best road level that the vehicle can vanquish at a given speed and the most outrageous speed that the vehicle can reach. In EV's, only the traction engine passes on force to the determined wheels. Thusly, the vehicle execution is completely directed by the force speed or torque-speed typical for the footing motor. A vehicle, to meet its operational essential, for instance, the fundamental increasing speed and grade capacity with the least power referenced above, the action inside and out conflicting force is required. [70]

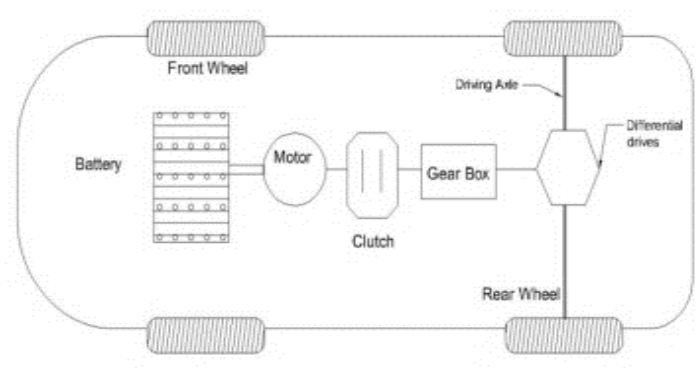


(b)

Fig. 3. (a) Conventional electrical vehicle drive system, (b) Desired output characteristics of electric conventional motor drives in EV's [1]

\subsection{EV Configuration With In Wheel Motor Drive}

The differential can also be eliminated with a drive motor if this uses a dual-motor system means. In this system, there have two motors coupled with different individual wheels utilizing fixed geared some of the motors are integrated into the wheel there is no need to use fixed gear to assembled in the system, [4] [7] gear system utilized is normally a planetary gear system, A standard planetary gearbox comprises of a sun gear, a ring gear, planetary gears, and a transporter. For the most part, the ring is grounded, while the sun is utilized as input and the transporter as the output. In the accompanying model, we will think about a double, motor incitation, where likewise the ring is utilized as a contribution to help to accomplish an augmentation of the proficiency of the planetary gear system. We think about the gear system in Fig. 1, where the sun, the ring, and the planet gear turn with speeds [46] so this system is simple and less bulky compared to the configuration of the conventional differential drive, [44] action has to be carried out by the mutual of these motors, so this motors a cannot be operated individual mode so they have to be coordinated their control enables to differential action The transmission-less sort can be rearranged to the differential-less sort if the differential apparatus is expelled, as showed in Fig. 5. Two electric-driven motors are introduced on the frame of the wheel and have joints given to transmit power to the wheels to give a capacity equivalent to the differential.

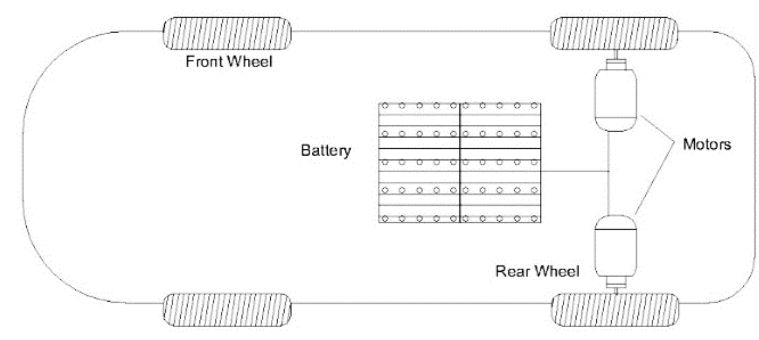

Fig. 4. Pure electric vehicle drive system (Cascade Type)

This Cascade type is also known as the direct drive system. It is also possible to eliminate driving axle totally means there is no driving shat connecting the motor to the wheels. This configuration requires because motors are generally high devices well the requirements of the wheel are low speed. And planetary gear device used in such type of system.
Control stability can be archive with different strategies. [43]

\section{Title Experimental analysis of Drivetrain}

This comparison is generally between two different drive systems which have been used in electric vehicles for the past 25 years. However, some of the drives are allowed high performance and smooth control and the same energy requirement some drive system configuration provides more space and light in weight on those point convention and differential-less dives have been compared. To show some positive results comes from the analysis.

\subsection{Subheading Single motor type differential use drivetrain}

In a car power train framework, the differential gear assumes an indispensable work in empowering the automotive also convert the motor torque to the drive wheels. When conventional vehicles used a single motor there have to use a differential. The differential is basically their gear system like so one gear is called pinion gear and collected to two axel gears. The nevertheless dependent requirement of turning the vehicle created a differential of speed between two opposite axels such that the vehicle can be turned. To make a turn in one direction for that $\omega 1>\omega 2$ should be greater than if the vehicle wants to turn the vehicle. The differential is utilized in terms of turning conditions without differential there is a possibility of sliding, loss of balance, and also effect on a lot of wear and tear on a tire. The differential framework comprises a system of gears that are fitted with one another.

If the vehicle is traveling at a constant speed to calculate basic power, energy, and seed relationship of the vehicle when vehicle operating as a motor for forwarding motion vehicle that's why to require tractive effort FT moving at velocity V. dynamic equation used for understanding the dynamics of the vehicle for different kinds of force input, input is a force which gets form electric motors or traction unit. When a vehicle is moving at a velocity of $(\mathrm{V})$ under a tractive effort of (FTE) then torque on the driving axle $(\mathrm{Tw})$ is equal to total tractive effort and radius.

$$
\begin{aligned}
& \mathrm{P}=\mathrm{F} \times \mathrm{V}=\frac{F}{S} \\
& \mathrm{E}=\mathrm{P} \times \frac{S}{V}
\end{aligned}
$$




$$
\mathrm{S}=\mathrm{E} \times \frac{V}{P}
$$

The effort required to move and propel the vehicle move ward, transmitted to the ground, through the drive wheel is known as tractive effort. In that tractive effort having two types as constant tractive effort and variable tractive effort, constant tractive means there is constant input available to run motor consider a vehicle of mass $\mathrm{M}$, moving at velocity $\mathrm{V}$, and slope of angle 0 , thus tractive effort should accomplish overcome the rolling resistance, aerodynamic drag acceleration of the cars, and the component of automotive mass acting downslope. Total Tractive Effort

$$
F_{T E}=F_{R R}+F_{G}+F_{A D}+F_{L A}+F_{A A}
$$

$$
\begin{aligned}
& \mathrm{F}_{\mathrm{TE}}=\mu_{\mathrm{rr}} \mathrm{mg} \cos (\boldsymbol{\theta})+\mathrm{mgsin}(\boldsymbol{\theta})+\frac{1}{2} \rho \mathrm{C}_{\mathrm{D}} \mathrm{A}(\mathrm{V}+ \\
& \left.\mathrm{V}_{\mathrm{AIR}}\right)^{2}+\left(\mathrm{m}+\frac{j}{r^{2}}\right) \frac{d v}{d t}
\end{aligned}
$$

$$
\omega w=\frac{v}{r}
$$

$T_{w}=\mathrm{FTE} \times r$

$$
\omega M=G \times \omega w
$$

Using the power balance equation the power on the electrical machine shaft can be equal to power delivered on the driving axle, since in that power transmission facing with mechanical gears arrangement like differential and gearbox because of this efficiency this can also accommodate the losses in the gear by substituting a value $\eta_{G}$.

$$
\begin{aligned}
& \mathrm{T}_{\mathrm{M}}=\frac{1}{\boldsymbol{G}_{G}} \mathrm{~T}_{\mathrm{W}} \\
& \mathrm{J}_{\mathrm{axle}}=\mathrm{G}^{2} \times \eta_{G} \times \mathrm{J}_{\mathrm{M}}
\end{aligned}
$$

$$
\begin{aligned}
& \mathrm{FTE}_{\mathrm{TE}}=\mu_{\mathrm{rr}} \mathrm{mg} \cos (\boldsymbol{\theta})+\mathrm{mgsin}(\boldsymbol{\theta})+\frac{1}{2} \rho \mathrm{C}_{\mathrm{D}} \mathrm{A}(\mathrm{V})^{2} \\
& +\left(\mathrm{m}+\frac{j}{r^{2}}\right) \frac{d v}{d t}
\end{aligned}
$$

$$
\begin{aligned}
& \frac{T_{W}}{r}=\mu_{\mathrm{rr}} \mathrm{mg} \cos (\boldsymbol{\theta})+\mathrm{mg} \sin (\boldsymbol{\theta})+\frac{1}{2} \rho \mathrm{C}_{\mathrm{D}} \mathrm{A}(\mathrm{V})^{2} \\
& +\left(\mathrm{m}+\frac{G^{2}}{\eta_{G} r^{2}} \times \mathrm{J}_{\mathrm{M}}\right) \frac{d v}{d t}
\end{aligned}
$$

$$
\begin{gathered}
\boldsymbol{G} \eta_{G} \mathrm{~T}_{\mathrm{M}}=\mu_{\mathrm{rr}} \mathrm{mg} \cos (\boldsymbol{\theta})+\mathrm{mgsin}(\boldsymbol{\theta})+\frac{1}{2} \rho \mathrm{C}_{\mathrm{D}} \mathrm{A} \\
(\mathrm{V})^{2}+\left(\mathrm{m}+\frac{G^{2}}{\eta_{G} r^{2}} \times \mathrm{J}_{\mathrm{M}}\right) \frac{d v}{d t}
\end{gathered}
$$

\section{2 cascade type multiple motor use drivetrain}

The study and calculation are proposed to assess the vehicle speed. [9] The controller takes vehicle longitudinal, parallel, and yaw speeding up signals as criticism utilizing the idea of state-subordinate input control. [67] The objective of the controller is to perfectly ideally control vehicle movement according to the driver's orders. [52] A battery of a huge amount of energy component joins as a battery gives the capacity to driven engines all the while. [54] The incorporation of ground-breaking processors, drives contraptions for electric motors have been improving, allowing complex control calculations to be executed on the simultaneously control unit of a multi-motor electric vehicle.[40][21] Reference signals are first resolved to use a driver order mediator to precisely decipher what the driver expects for the vehicle direction. [17] The multistage planetary gear transmission system is mainly

Used in complex machines for instance industrialist machinery due to its compact structure, high load carrying capacity, we have analyzed the dynamic speed ratio by simulation and allow friction in gear teeth to find losses for that $\mathrm{f}$ friction equation is used.

$f=\delta \mu F$

Because of this we utilize planetary gear system with fine lubrication to lessen amount of friction coefficient of friction and dynamic coefficient is required as a natural additives, there for to calculate the coefficients of friction there is two formula derived by Buckingham and Kelley-Lemanski to find coefficient of friction according to conditions. Both formulas are used at special conditions when gear teeth are immerged at partially elastic hydrodynamic lubrication state, then Buckingham semiempirical formula used [10] is given as the following equation:[30]

$\mu B=0.05 e^{-0.125 v}+0.002 \sqrt{ } v$

on the other hand full elastohydrodynamic lubrication state, and the full elastohydrodynamic lubrication theory is used to calculate the friction coefficients.at the time Kelley-Lemanski formula utilize.[30]

$\mu_{k}=0.0099 \frac{1}{1-R / 45} \lg \left[\frac{3.5 \times 10^{8} \omega}{\eta_{0} V_{s} V_{l}^{2}\left(r_{p}+r_{g}\right)^{2}}\right]$ 
Planetary gears system interdependent on numerous gears sun gears, planet gears and ring gear those have frequency such as $\mathrm{f} s, \mathrm{f} p$ and $\mathrm{f} a$ in between them the relation between the tooth meshing frequency and rotational frequencies. Basically, gear frequency can be depend upon the number of tooth on gears and face width

of gears $N S, N P, N a$ respectively. There is general formula to calculate tooth meshing $\mathrm{f} m$ is below and separate gear part equation is supportive to this equation.[58]

$$
\mathrm{f}_{m}=N a \mathrm{f} c=N P\left(\mathrm{f} p+\mathrm{f}_{c}\right)=N S\left(\mathrm{f}_{S}-\right.
$$

$\left.\mathrm{f}_{c}\right)$

planetary gear and ring gear tooth frequency evaluates from this equation a ration of gears [mathe maticam model hindwai]

$$
\mathrm{f}_{p}+\mathrm{f}_{c}=\mathrm{f}_{c}(\mathrm{Na} / \mathrm{NP})
$$

and relative gears frequency and gear ratio in between the sun gears related to ring gear.

$$
\mathrm{f}_{S}-\mathrm{f}_{c}=\mathrm{f}_{c}\left(\mathrm{Na}_{\mathrm{N}} / \mathrm{N}_{s}\right)
$$

for the calculation of gear ratio and speed variation in between input and output gears is also helpful to vary power losses in gears, the power losses depend upon gears ratio as high difference in ratio power losses is comparatively high this is happened due to in general gear meshing friction and gear pocket losses. But epicyclic gear transmission is having high torque capacity, power to weight ratio, power to size ratio torsional stiffness comparatively differential transmission, additional backlash is low that efficient performance gives smooth acme efficiency. Nevertheless, the planetary gear system consists of minimal friction and that can be calculated by upper formulas. [17] The controller by then adjusts the slowing down/throttle outputs reliant on the irregularity between the vehicle response and the mediator command. A test vehicle equipped with four inwheel electric motor, vehicle sensors, correspondence transports, and DSPACE quick prototyping gear is instrumented and the control execution is affirmed through vehicle taking care of tests under different driving conditions.[8] The propulsive force $F$ available from the propulsion system is partially consumed in overcoming the road load, Fw. The net force, F-Fw, accelerates the automotive (or decelerates when FW exceeds F). The acceleration is given by

$$
\mathrm{a} .=\frac{F-F_{W}}{k_{m} \cdot m}
$$

where $\mathrm{km}$, is the rotational inertia coefficient to make up for the clear increment in the vehicle's mass due to the on-board pivoting mass. [31]

$$
\mathrm{P}=\frac{2 \pi N T}{60}
$$

Where, $(\mathrm{P})$ is power consumption in Watts, $(\mathrm{N})$ is speed of rotation in rpm; (T) is torque in N-m. Three complete unrest of ring gear has been simulated and final speed is considered for additional examination.

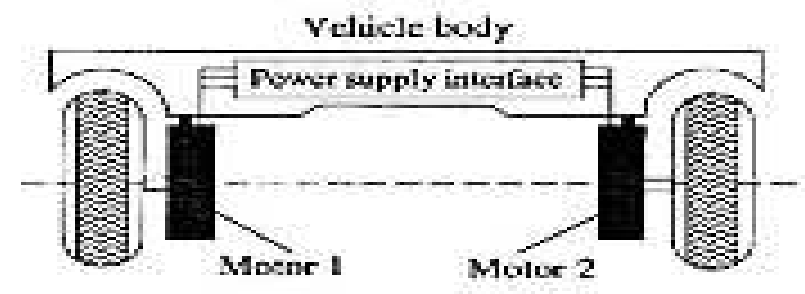

Fig. 5.Multi motor type differential use drivetrain [38]

\section{Simulation Analysis}

Electric vehicle EV's with two distinctive autonomous back wheel drives can work as a differential capacity implies that differential conceivably replaces by motors.[18] Multi-engine applications are starting at now a "legitimate" decision in outstandingly mentioning contraptions by superseding mechanical coupling. Here, Electronic Virtual Line-Shafting (EVLS) to synchronize two synchronous Induction Motors (IM) or some other wheels for an electric vehicle feed (considering the level ride case) by singular the inverter is presented. [7] This sort is gotten from the unraveling of the transmission-less type. Two motors are mounted into the wheel side with decrease gears provided for drive the wheels, the transmission-less sort can be smoothed out to the differential-less type if the differential mechanical assembly is emptied. Two motors are presented on the body side and have joints given to transmit the ability to 
the wheels to give a limit equal to the differential. This sort is in like manner saw as the quick drive type. [1][

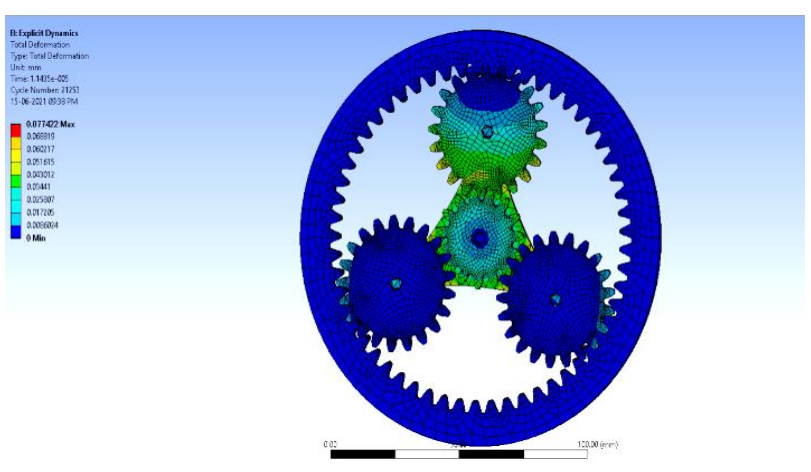

(a)

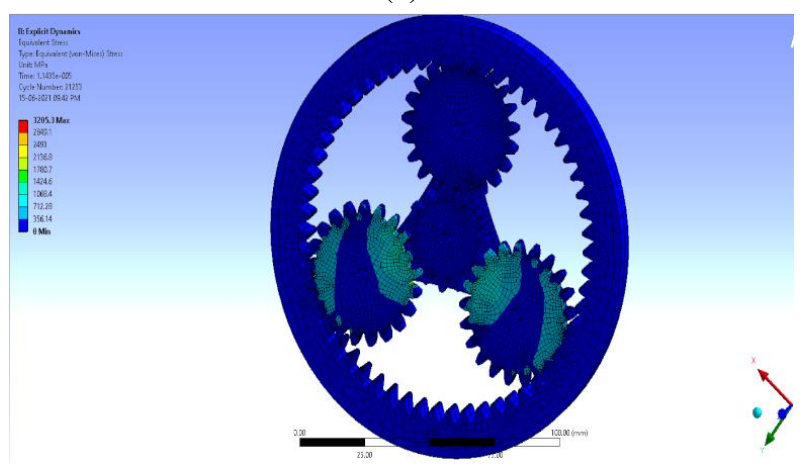

(b)
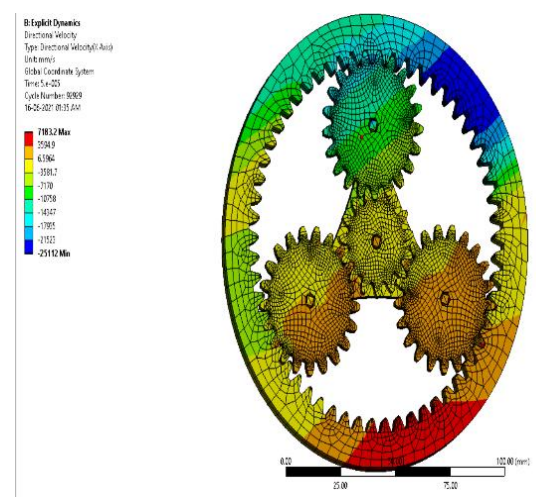

(c)

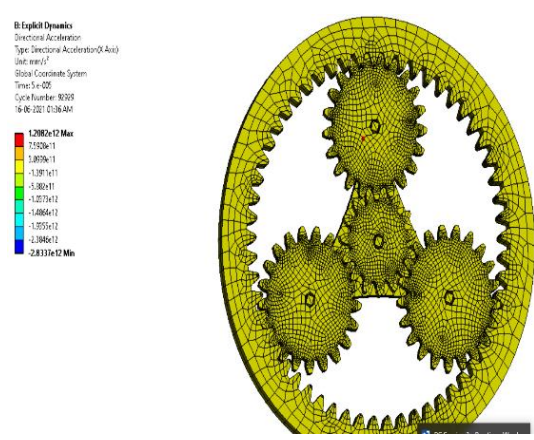

(d)
Fig. 6. Simulation analysis of epicyclic gear train categorized to (a) total deformation (b) equivalent stress (c) directional velocity, (d) directional acceleration.

The traction control is developed to guarantee the EV dynamics and stability in the absence of differential gears. Utilizing two in-wheel electric driven consume it conceivable to have force and speed control in each wheel. For Electric vehicles, in this work, we studied the usage of two electric motors joined to a planetary gear train. Specification of epicyclic gear such as ring gear has 48 gear teeth and for sun and planetary gear have 22 and 18 teeth respectively. The amalgam work of the torque and the speeds of the electric motors of the sun and the ring of the planetary gear make them work at favored estimations of viability over a singular motor. Through parametric progression, we can assemble the typical useful over a convention drivetrain example of $9.34 \%$ concerning a singular motor during the giving of force and $11.86 \%$ during recovery of intensity. There are a few powers consider in the planetary gear system with mass $0.66016 \mathrm{~kg}$ to consider the planet centrifugal forces considering friction and dynamic coefficient 0.4 and 0.1 respectively. In addition, a technique is additionally proposed to incorporate, centrifugal, inertia, and Coriolis forces in the decreased FEM of the bearer which has an unbending turning movement, with the objective that the model is pertinent to quick turning. The lattice focuses on change in the limited course in the consolidated ring model. [40][41] The proposed acceleration pedal control system uses the vehicle speed, which is extraordinary according to wheel speed depicted by a slip in driving. For this situation, a summed up neural framework.

Powerful oil of the differential framework assure that the metal to metal mesh into the gears is kept away from. Likewise, the lubricants additionally go about as a warm component to successfully disseminate the heat generated because of frictional opposition and also torque losses. For the plunged oil framework, the Utilization of oil prompts lost transmission power and the loss increments with speeding up.

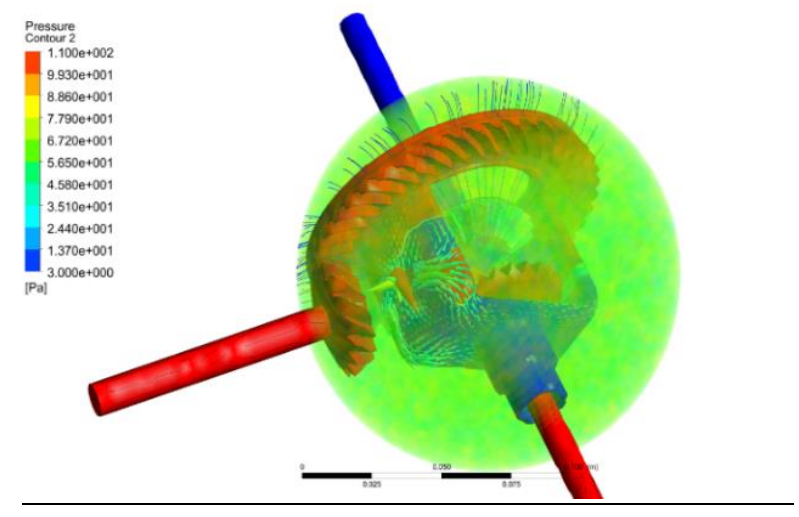

(d) 


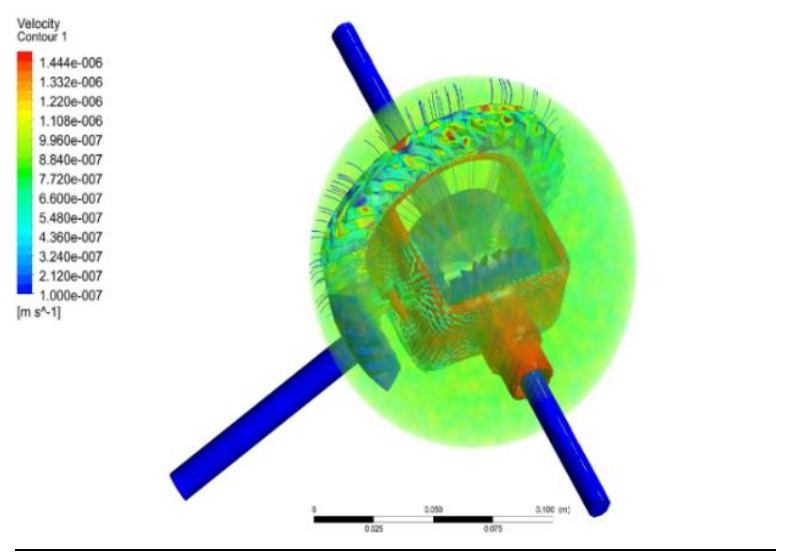

(e)

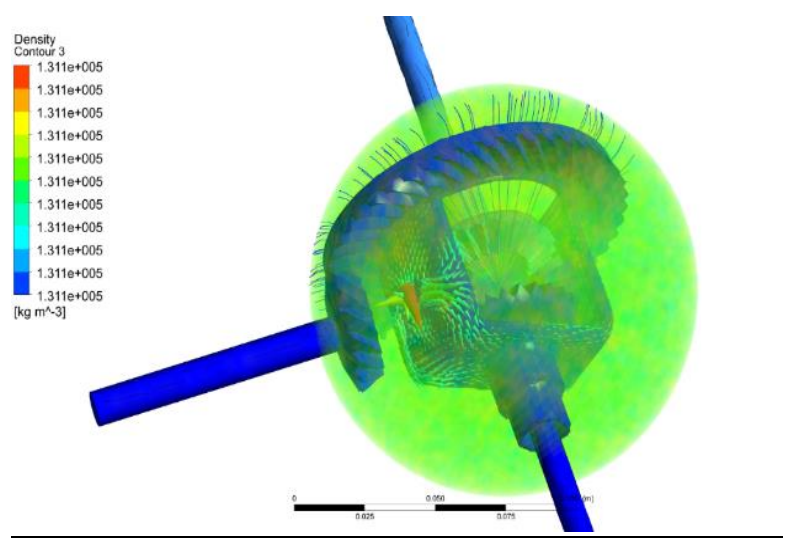

(f)

Fig. 7. CFD Simulation analysis of differential with fluid stream categorized to (d) pressure (e) velocity (f) density.

In some researchers ' the study, an exceptionally presumed computational model is created to research rotational power losses of a real differential transmission system inside a wide range of speed and work arrangements. In fig (e) velocity is mainly counter in the main bevel gear and tend to create more patch into teeth of a gear. It is anticipated that gears system power losses there are two types of losses in differential system load-ward and load-independent losses load-dependent consist of gear mechanical and bearing mechanical lose and independent loss contains gear drag, gear pocket, and bearing viscous. The force utilization of the system is looking during the gear revolution. Minutes for driving gears and Ring gear are considered at inception as the focal point of revolutions and afterward relating power utilizations are determined to utilize equation of intensity and force. Certain analysis has been done by CFD fluent as stream represents the flow of an ELASTO fluid mechanics Lubrication (EHL) over the gears, high viscosity lubrication leads to disturbance and nugatory losses in the casing as fig. (d) Shows the high pressure created on the engaged gears considering high density in fig (f) as well. The viscosity of lubrication is directly encountered on the main gears fig. (e) due to large surface area, so considering these factor losses which mention earlier is ascends gradually respectively the speeds of gears.

\section{Result and discussion}

This such system allegiance to control various parameters of speed to make it easier to turn the vehicle and accelerate the speed with precision the control system is used in EV's as block diagram given below. [21] In this paper researcher calculated power rating, gear ratio, Rated Speed (rpm) Maximum Speed, by using MATLAB simulation for all types' motor this information can be used for this review paper as a comparing purpose and to get better visualization The motors information picked is for the financially accessible tests of these motors. Plainly, increasingly explicit engines can be intended for vehicle applications, yet such data is not available for this study. Considering the vehicle data, the power important to travel at the most extraordinary speed is $41 \mathrm{~kW}$. The most generally utilized engines motors in an electric vehicle as a determined mechanical engines power for speeding up and converter volt-ampere (VA) need for each engine has shown up in Table I [31]

\begin{tabular}{|cccccc|}
$\begin{array}{c}\text { Types of } \\
\text { motor }\end{array}$ & $\begin{array}{c}\text { Rated } \\
\text { Speed } \\
(\mathbf{r p m})\end{array}$ & $\begin{array}{c}\text { Maximum } \\
\text { Speed } \\
(\mathbf{r p m})\end{array}$ & $\begin{array}{c}\text { Gear } \\
\text { Ratio }\end{array}$ & $\begin{array}{c}\text { Power } \\
\text { Rating } \\
(\mathbf{k w})\end{array}$ & $\begin{array}{c}\text { Converter } \\
\text { Rating } \\
(\mathbf{k V A})\end{array}$ \\
\hline Induction & 1750 & 8750 & 5.6 & 65 & 79 \\
\hline BLDC & 4000 & 9000 & 5.9 & 86 & 92 \\
& & & & & \\
\hline SRM & 4000 & 20000 & 13 & 68 & 113 \\
& & & & & \\
\end{tabular}

Table. I. comparing motor performance of three motors

In the simulation, analysis simulation can clearly show power variation and losses as well in two mechanisms. In the case of differential maximum pressure is generate on majority gear in fig (d), and high velocity of main gear (e). So that leads to resisting the rotation. Now, planetary shows low pressure due to less dense gear and just a slim layer on the surface. the planetary gear rotation power is provided at $3000 \mathrm{rpm}$ rate to the planetary we found certain esteem and there is 0.94596 maximum deformation found for corresponding to time 5.e-005 s. moreover, total acceleration $3.0939 \mathrm{e}+012 \mathrm{~mm} / \mathrm{s}^{2}$, directional velocity $9201.8 \mathrm{~mm} / \mathrm{s}$ at successively maximum rate as directional acceleration is niceties value $1.2082 \mathrm{e}+012 \mathrm{~mm} / \mathrm{s}^{2}$. as the following result is depicted in graphical format. In the total acceleration chart, we can interpret that acceleration is incessantly 
increase with respective time. Since friction is comparatively less the planetary gear therefore acceleration of gear is happened there as smooth.

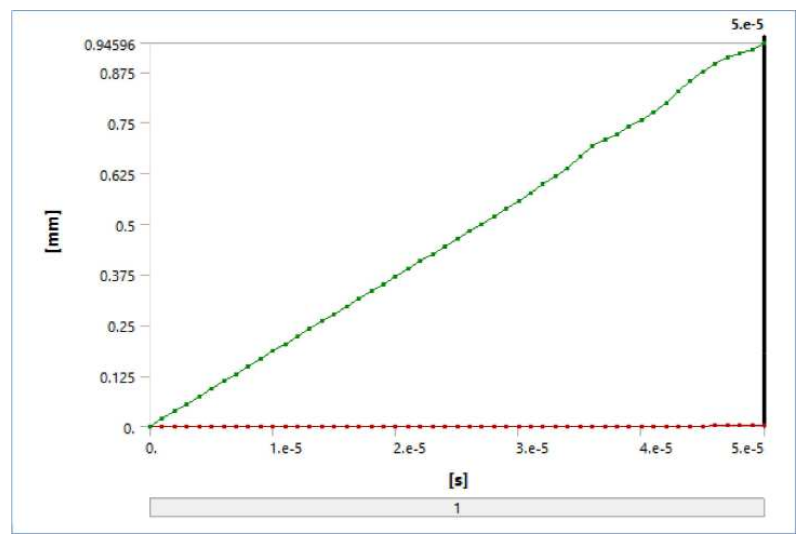

(a)

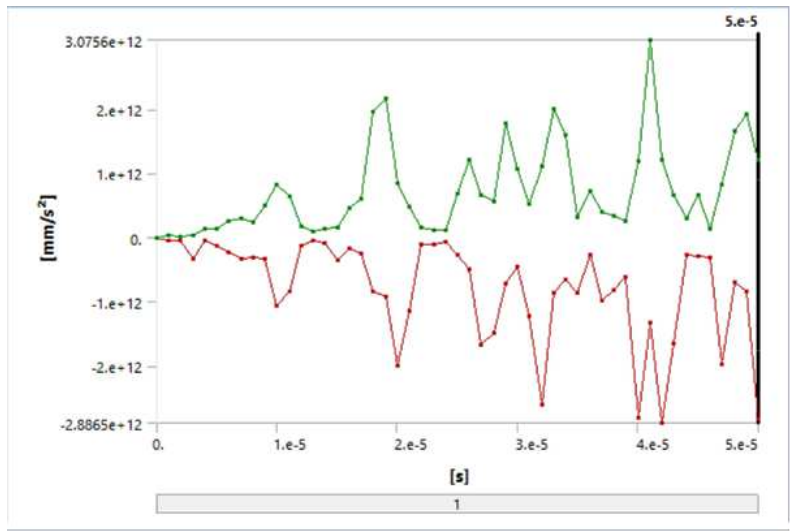

(b)

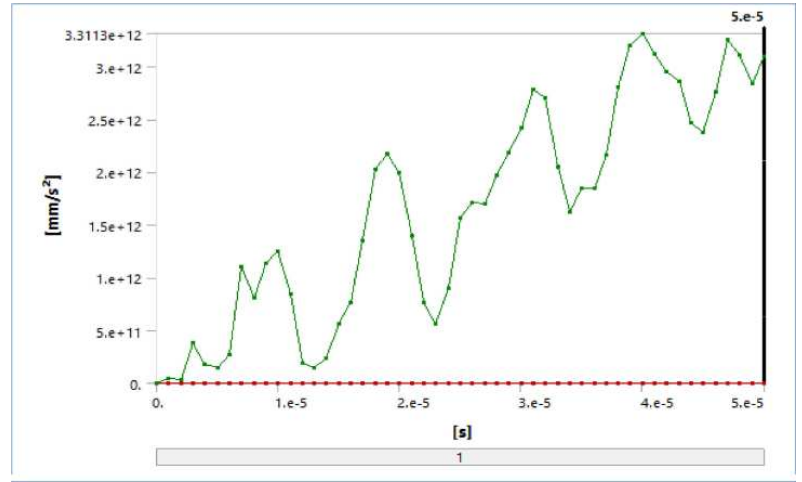

(c)

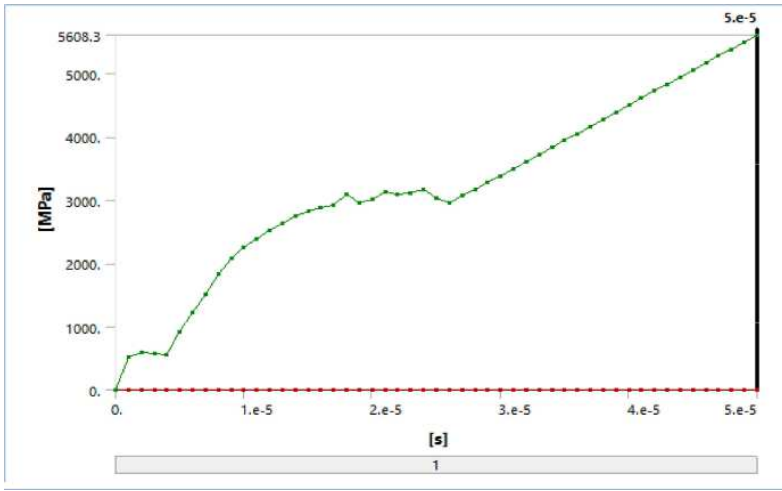

(d)

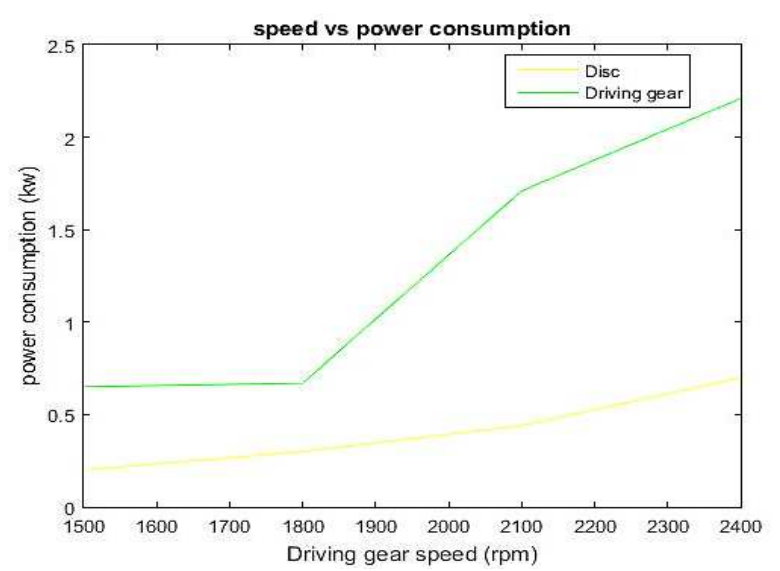

Fig.8. Graphical Result For Epicyclic Gear (A) Deformation, (B) Velocity, (C) Acceleration, (D) Stress Equivalent In Gears.

(e)

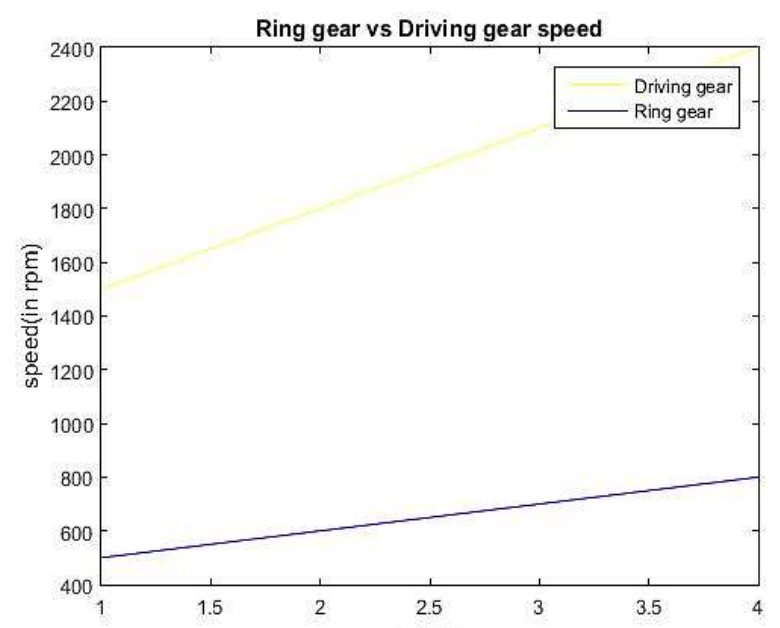

(f)

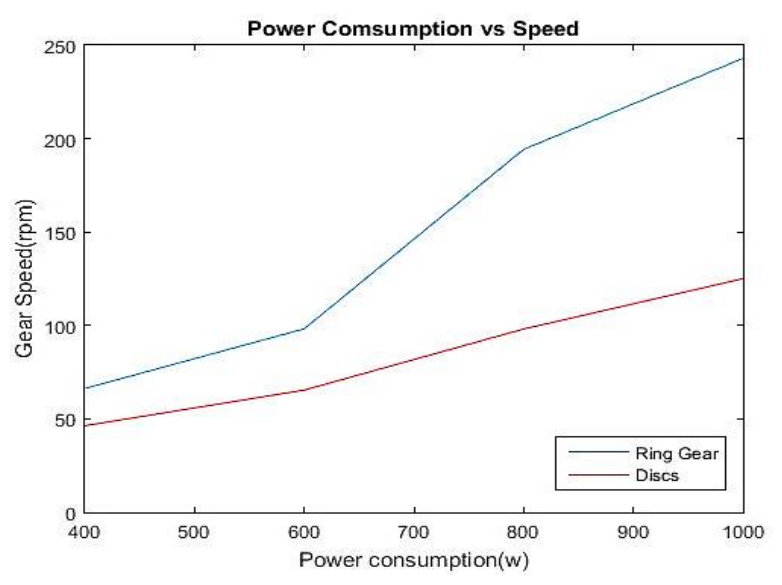

(g)

Fig. 9. Case depictions power consumption comparison in differential: (e) Driving gear and ring gear, (f) driving gear and disc, (g) actual gear and discs for ring gear [5] 


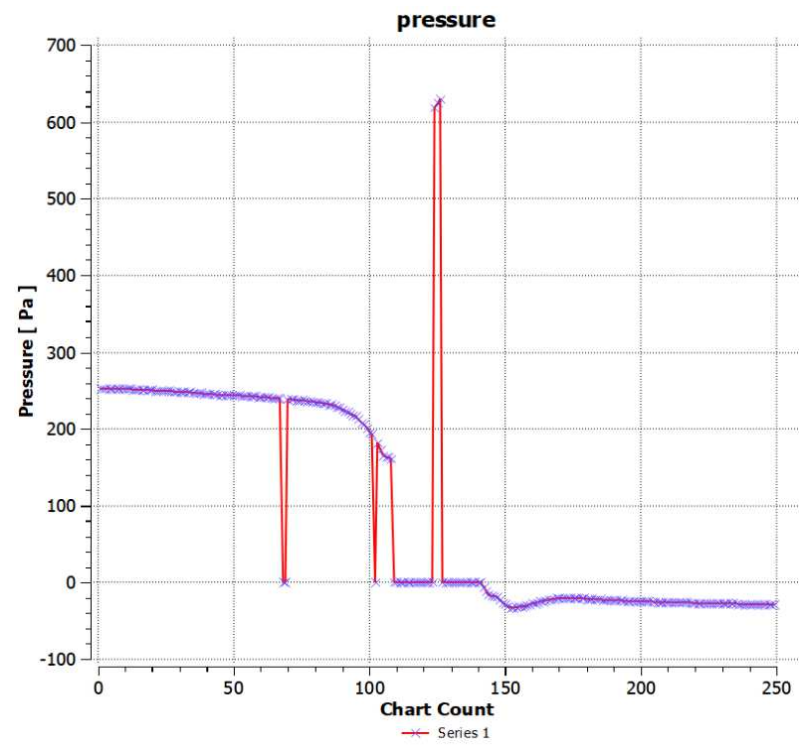

(i)

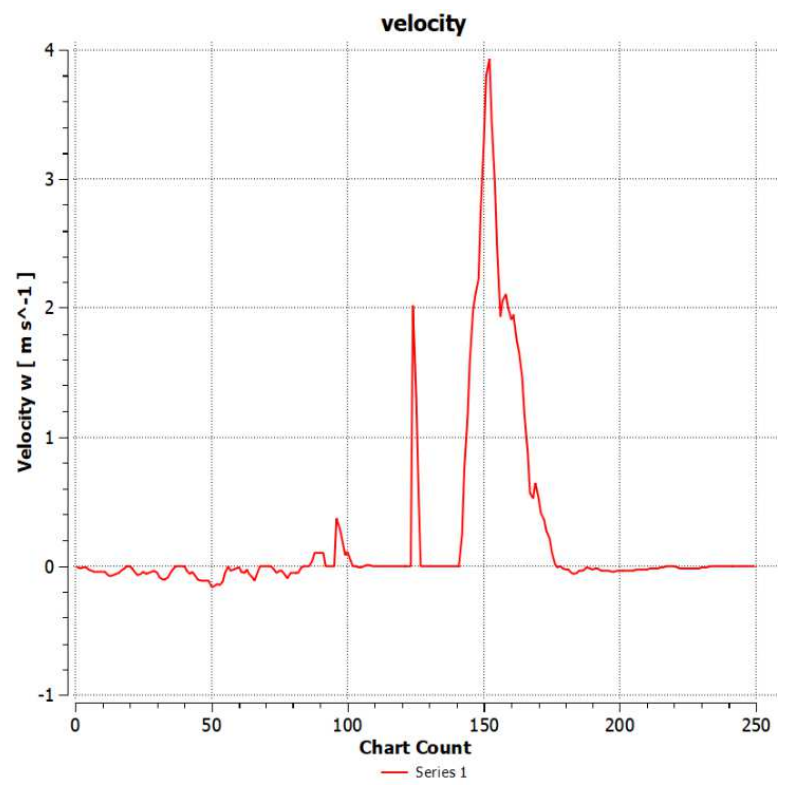

(j)

Fig. 10. (i) Graph of pressure inside the differential casing (j) Graph of pressure inside the differential casing

For the comparisons of differential power output chart represent a variation of speed and power consumption previous researches [5] have analyzed the power consumption ratio in various parts of the differential. Renjith, $\mathrm{S}$ el at. Have calculated the effect of fluid motion in the casing of differential and shows the result with dynamic simulation analysis and they find variously reasoned to power losses in the differential gear system. Respective pressure in a surge at the same time when the velocity of gear increases and more 600 bar inside the casing in Fig 10 (i) and (j) this experimental study conducted considering the heavy lubrication into the casing of differential gear system. They calculate the speed variation in planetary gears, sun gear, and ring gear. Similarly, we have calculated the research gap for example effect of losses by considering the effect on pressure and velocity. As our study concern, Due to high viscosity of fluid pressure in the initial condition is high and velocity is corresponding low as a result of losses occur during the rotation of gear as lubricant filled $n$ pocket find wade to gears.

\section{Performance analyses output characteristic of EV's drives motors.}

As an electric vehicle is more reliable and conventional is driving because of flexible to control the direction, in turn, they have impactful benefits upon internal combustion engine vehicles such as specific direction control possibility, quick torque response and individual control of both single rear wheel discuss previously in EV's there are several motors are selected for the vehicle as per framework design consideration criteria, such are many motors are available with varying power, torque and acceleration power rate like induction motors Cage IMs are widely accepted as the most likely possibility for the electric drive of HEV's, owing to their reliability, ruggedness, low maintenance, low cost, and capacity to work in unfriendly situations. They are especially appropriate for the afflictions of mechanical and traction drive conditions. Now a day, an IM drive is the most experienced tech among different commutator lesser motor engine drives. [13] PM brushless motors are most capable of competing with IMs for electric propulsion. [21]These motors have many numerous merits, indeed 1) the total mass, weight, and volume have significantly deteriorated for a given wheel power (high power density); 2) higher efficiency, and 3) heat is efficiently throughout to the atmosphere with effective rate. [12]

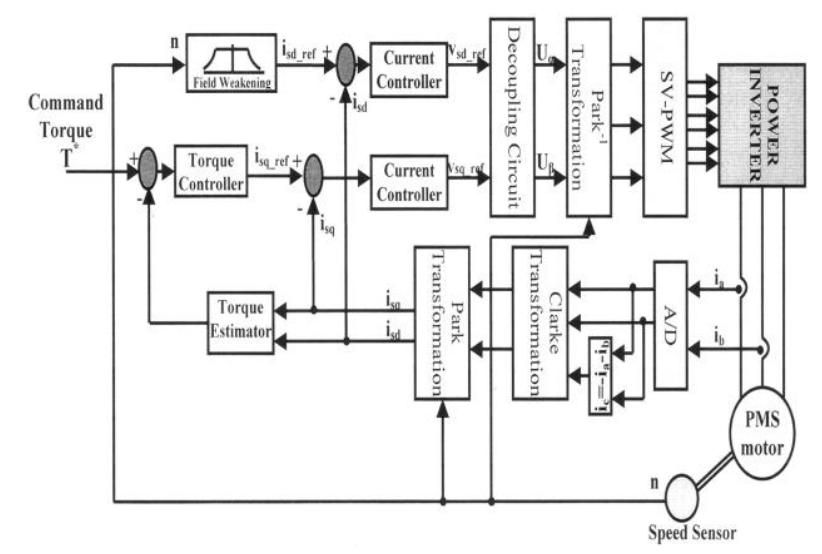

Fig. 11. Block-diagram of an electric drive control system for PMS motors.

Many options are available in the model of EV's that categories the properties of a vehicle such as speed, velocity, range, and battery capacity and models listed by dossers from various treaties. This table is present in an intention to compare the power of EV's, but models taken are only manufactured after 2021, past models configuration available in [14] motor are used with a variety of types induction motor (IM), Permanent 
magnet Synchronous motor (PSMS), Brushless motor (BM), AC synchronous motor (ACSM), Permanent magnet Synchronous reluctant motor (PSRMS), reluctant motor $(\mathrm{RM})$.

\begin{tabular}{|c|c|c|c|c|c|c|}
\hline \multirow[b]{2}{*}{ EV's Model } & \multicolumn{3}{|c|}{ Nominal } & \multicolumn{3}{|c|}{ Energy } \\
\hline & Year & $\begin{array}{l}\text { Range } \\
\text { (km) }\end{array}$ & $\begin{array}{l}\text { Power } \\
(K . W)\end{array}$ & $\begin{array}{l}\text { Torque } \\
\text { (N.m) }\end{array}$ & $\begin{array}{c}\text { Capacity } \\
(K W h)\end{array}$ & $\begin{array}{c}\text { Motor } \\
T_{\text {Ype }}\end{array}$ \\
\hline Renault Zoe & 2012 & 400 & 80 & 225 & 52 & ACSM \\
\hline ECOmove Qbeak & 2012 & 250 & $40+$ & 490 & 27 & DC,IM,PM \\
\hline Tesla Model S & 2012 & 560 & 615 & 1,300 & 75 & IM \\
\hline \multicolumn{7}{|l|}{ Smart Smart electric } \\
\hline drive & 2013 & 145 & 60 & 160 & 75 & RM \\
\hline Rayttle E28 & 2014 & 130 & 4 & - & 9.9 & BM \\
\hline \multicolumn{7}{|l|}{ Electra Meccanica } \\
\hline SOLO & 2015 & 161 & 61.14 & 128 & 17.3 & PMSM \\
\hline \multicolumn{7}{|l|}{ Mercedes-Benz - B- } \\
\hline Class Electric Drive & 2015 & 200 & 100 & 310 & 36 & PMSM \\
\hline Tesla Model X & 2015 & 565 & 375 & 660 & 100 & IM \\
\hline Renault Twizy & 2016 & 100 & 4 & 57 & 6.1 & IM \\
\hline Chevrolet - Bolt EV & 2016 & 383 & 150 & 360 & 65 & PMSM \\
\hline Kia Soul EV & 2016 & 150 & 90 & 285 & 27 & PMSM \\
\hline Kyburz Race & 2016 & 183 & 45 & 140 & 19.2 & Dc Motor \\
\hline BYD - e6 & 2016 & 400 & 90 & 450 & 61 & PMSM \\
\hline \multicolumn{7}{|l|}{ MW Motors - Luka } \\
\hline EV & 2016 & 300 & 55 & 110 & 21.9 & PMSM \\
\hline Nissan - Leaf & 2016 & 252 & 80 & 320 & 40 & ACSM \\
\hline Mitsubishi - i-MiEV & 2016 & 170 & 47 & 180 & 16 & PMSM \\
\hline Mahindra - e-Verito & 2017 & 180 & 30.5 & 91 & 18.55 & IM \\
\hline \multicolumn{7}{|l|}{ Motores Limpios } \\
\hline Zacua & 2017 & 160 & 34 & -- & 15.6 & ACSM \\
\hline \multicolumn{7}{|l|}{ EV Electra QUDS } \\
\hline EE & 2017 & 800 & 400 & 315 & 45 & PM \\
\hline Tesla Model 3 & 2017 & 400 & 211 & 450 & 62 & PMSRM \\
\hline BMW - i3 & 2017 & 246 & 135 & 270 & 42.2 & PMSM \\
\hline Peugeot - e208 & 2017 & 340 & 100 & 260 & 50 & PMSM \\
\hline MG Motor ZS EV & 2018 & 263 & 105 & 353 & 44.5 & PMSM \\
\hline & & & & $210 \mathrm{lb}$ & & \\
\hline Kia Soul EV & 2018 & 179 & 81 & $f t$ & 30 & PMSM \\
\hline \multicolumn{7}{|l|}{ Micro Mobility } \\
\hline Systems - Microlino & 2018 & 215 & 11 & 100 & 1404 & PMS M \\
\hline \multicolumn{7}{|l|}{ Hyundai - Kona } \\
\hline Electric & 2018 & 470 & 150 & 395 & 39.2 & PMSM \\
\hline Kandi - K27 & 2018 & 161 & 45 & 150 & 18 & ACSM \\
\hline Kandi - K23 & 2018 & 302 & 49 & 175 & 41.4 & ACSM \\
\hline \multicolumn{7}{|l|}{ Jaguar Land Rover - } \\
\hline I-Pace & 2018 & 350 & 294 & 696 & 294 & PMSM \\
\hline Aiways U5 & 2019 & 400 & 150 & 310 & 63 & PMSM \\
\hline Sono Motors Sion & 2019 & 250 & 120 & 290 & 35 & ACSM \\
\hline Skoda - CITIGOe IV & 2019 & 260 & 61 & 212 & 36.8 & PMSM \\
\hline Tata Motors Nexon & 2019 & 300 & $127 b h p$ & 245 & 30.2 & PM \\
\hline \multicolumn{7}{|l|}{ Ford Mustang } \\
\hline Mach-E & 2019 & 491 & $351 \mathrm{hp}$ & 580 & 88 & ACsM \\
\hline SEAT - Mii Electric & 2019 & 260 & 82bhp & 212 & 36.8 & DC \\
\hline Audi e-tron 55 & 2019 & 328 & 100 & 561 & 95 & PMSM \\
\hline Volkswagen - ID.3 & 2019 & 550 & 150 & 310 & 58 & $\begin{array}{l}\text { PMSM } \\
\text { IM and }\end{array}$ \\
\hline NIO - ES6 & 2019 & 510 & 480 & 840 & 100 & PM \\
\hline
\end{tabular}

$\begin{array}{lcccccc}\text { Dacia Spring } & 2020 & 225 & 33 & 125 & 26.8 & \text { PM } \\ \text { Kia Soul EV } & 2020 & 391 & 204 & 395 & 27 & \text { PMSM } \\ \text { Xpeng P7 } & 2020 & 552 & 196 & 390 & 80.87 & \text { PMS } \\ \begin{array}{l}\text { Xpeng P7 } \\ 2020\end{array} & 706 & 316 & 655 & 80.87 & \text { PMSRM } \\ \text { Tesla Model Y } & 2020 & 509 & 258 & 527 & 80 & \text { PMSRM } \\ \begin{array}{l}\text { Polestar - 2 } \\ \text { Honda - Clarity }\end{array} & 2020 & 470 & 300 & 660 & 78 & \text { PMSM } \\ \begin{array}{l}\text { Electric } \\ \text { Tesla Model 3 }\end{array} & 2020 & 143 & 100 & 256 & 17 & \text { ACSM } \\ \begin{array}{l}\text { Tesla Model 3 } \\ \text { Lightning - Lightning }\end{array} & 2020 & 518 & 258 & 510 & 75 & \text { IM } \\ \text { GT } & 2020 & 240 & 300 & 4000 & 44 & \text { PMSM } \\ \begin{array}{l}\text { Volkswagen - ID.4 } \\ 2020\end{array} & 496 & 201 \mathrm{hp} & 310 & 52 & \text { PMSM }\end{array}$

Table. II. Data on the Ev's Model Manufacture After 2012.

DC motors have been noticeable in electric impetus because their torque-speed characteristics are suitable for the footing prerequisite well, and their speed controls are basic. Be that as it may, dc motor drives are more disadvantageous to the normal facility have a bulky construction, low efficiency, low reliability, and a higher need for maintenance, mainly because of the addition of the mechanical commutator (brush), Regardless of whether intriguing advancement has been made with elusive contacts. [16]

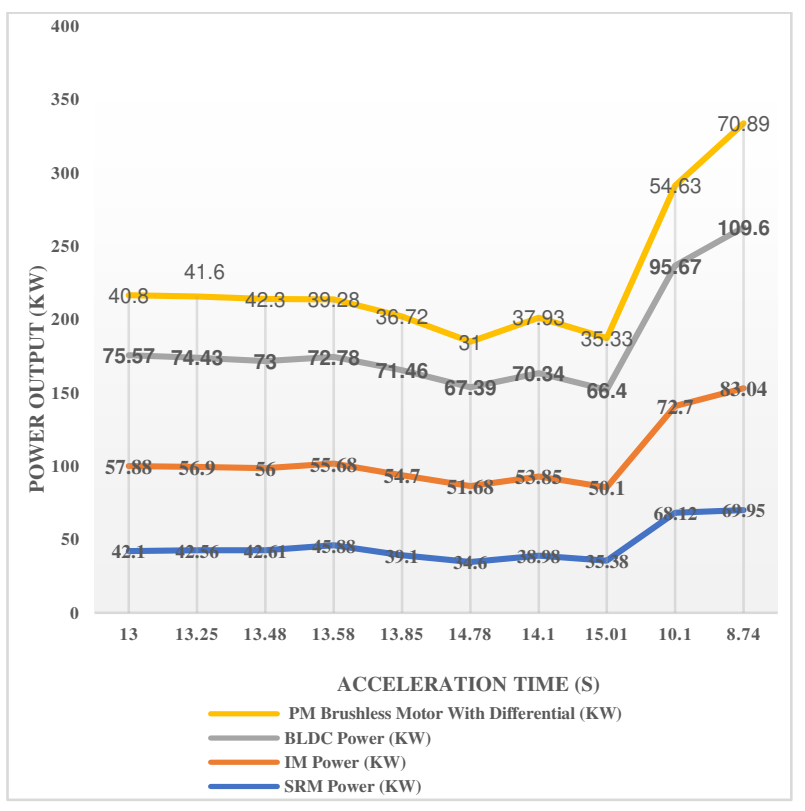

Fig. 12. Comparison Output characteristic of EV's drive motors and conventional drives. [6]

A switched reluctance motor is relevant to operating management has a few highlights, containing straightforward development, high reliability, possible operation in high temperature, inherent fault tolerance, 
and low manufacturing cost makes it increasingly appealing for electric vehicle applications. [29]In any case, enormous torque swell, acoustic clamor, but the vibration is its significant disadvantage. Follow given below charts show speed composition between different electric motors speed rate and conventional differential use motors rating [11]

\section{Conclusions}

In this paper, we explored the comparative study between differential used electric vehicles and differential less electric vehicles. By analyzing explicit dynamics and computational fluent for the differential simulation and planetary and calculated the statics result on software bases. Also compendium various kinds of related paper according to them different losses as. Two essential sections of gears turn influence losses are (1) Drag mishaps identified with the resistive force of the oil or velocity of air (or an oil-air mix) alongside the side faces and edge of gears, and (2) Pocketing power losses that is Churning power loss (CHPL) related with the pumping of the fluid medium from pockets framed into adjoining teeth of a gears network interface at the time of engaging of high velocity spur or helical gears, the combination of air and oil is progressively compacted and extended in the intertooth gaps bringing about huge warming and power losses called as air-oil taking force misfortunes.. [5] In addition, there are numerous reason of such losses, the essential ones oil churning, and windage that are available because of oil drag on the fringe and faces of the gear teeth, pocketing/ squeezing of lubricant from the cavities of the gear mesh, and viscous scattering of orientation. So losses from these 2 gatherings are regularly practically identical under highload, low-speed conditions, the acceleration loss were displayed to rule over the heap subordinate. Windage power loss (WPL) is another reason for power losses as casing half filled with lubricant and remain is air counter on the gear teeth surface as fluid drag experienced at high gear spinning.

The energy deteriorates at large pace acceleration conditions. There is the root of reason to generate the pocket and drag mishaps we have shown through the simulation pressure and velocity on the differential is comparatively higher than planetary gear system high pressure and velocity of ELASTO fluid mechanics Lubrication (EHL) wade to turn gear smoothly. As this lubricant fluid has a high density, therefore high-pressure $1.100 \mathrm{e}+002$ and velocity on various gears have been analyzed in differential simulation. The turbulent flow of liquid in the casing is responsible for losses i.e. Drag mishaps with the resistive force of the oil or velocity and on the other hand, in planetary gear level of lubrication is low. We got a point on a specifically oriented conclusion for the differential losses as an epicyclic gear control system rear-wheel torque control by fieldoriented control (FOC) method is commonly used for permanent-magnet synchronous motor (PMSM) control. The FOC system typically uses cascade control loops among with a few proportional-integral (PI), controllers for speed, position, and torque force control, quickening signals as feedback utilizing the idea of state-subordinate feedback control extensive the controller is to ideally control the vehicle direction movement as indicated by the driver orders climate driver need to turn controller additionally help to make turn vehicle by making the variety in speed between two-wheel the system diagram is shown in fig.7. [16]

In these studies presented, we found losses of differential by which mechanical assemble and lubrication in differential high viscosity and extreme pressure used bevel gears with low torque capacity those make power absorption by fluid interaction, rolling friction-related with the arrangement of an ELASTO fluid mechanics Lubrication (EHL) film between meshing teeth and contact curvatures and other detailed losses have been discussed in the paper.

On the other hand in the case of pure electrical the driven system (Cascade Type) means motors directly assembled into a wheel with planetary which is high torque capacity, power to weight ratio, power to size ratio torsional stiffness comparatively differential transmission, and no need mechanical coupling, shaft, to connect wheel so losses chances are negligible as compared to the differential mechanical system used, but the motor rpm is tremendously high in some case of motors so therefor there in additional planetary gear system to simplify heavy rpm problem. There is a dossier of various motors that are used in the electric vehicle compared concerning speed, power, and torque. Comparative study says that pure electrical driven configuration is more conventional, efficient than differential used conventional configuration vehicle system.

\section{Declarations}

\section{Acknowledgements}

During this research work we have to utilize the simulation software in order to show and analyse power comparison in between two drive transmission and research work based on compendium study as well as analysis, therefore this study initially start by single author and later on, under the guidance we have successfully completed our work with our own finance. We thanking to pote institute of give support and give facility to operated tech machinery for analysis study. In additional, I pleased to couther guided this through this research process and give the appropriate to this comparative analysis.

\section{Competing Interests}

The authors declare no competing financial interests.

\section{Authors' Contributions}

First author provided fundamental ideas and wrote the manuscript. Conceptualization, Methodology, Formal analysis, Validation, gap finding, collection of resource material Formal analysis, Investigation, Data correction, the trial and simulations. Co-author was guide of the 
provided all support conditions. Conducted proof reading and made some critical revisions and assisted with building up the research framework. All authors read and approved the final manuscript.

\section{Funding}

Not applicable.

\section{Authors' Information}

Abhijeet Dhulekar, born in 2000, is a research scholar in department of mechanical, P. R. Pote (Patil) College Of Engineering And Management, Amt. Maharashtra, India. $\mathrm{He}$ completed undergraduate at mention engineering institute. In additional, having three years of research experience at undergrad and have done many academic project, Because of having two paper published and at present five papers are under review process. Furthermore he have published five patent and one copyright at various internationally. He have successfully attended seven international conference as well as one national conference. His research interests include connected vehicles, vehicle energy-efficient driving control, vehicle dynamics and control.

Pankaj ardak, is currently at a position of associated professor in mechanical department at Dr.Rajendra Gode Institute of Technology and Research Amravati. He have completed is M.tech and he nominated with doctorate in the field of production engineering. Moreover he have published 8 research papers and attended 13 conferences. His research interests include automation. Production, energy and automobile field and get several patent in regard field.

\section{Availability of Data Materials}

In order to conduct this research we have refer various material such as online research papers, books, design data book of machine design to calculate coefficient of friction. Our numerical calculation is completely based on lecture notes and data books of electric vehicle.

\section{References}

1. Xue, X. D., Cheng, K. W. E. \& Cheung, N. C. Selection of Electric Motor Drives for Electric Vehicles. Australasian Universities Power Engineering Conference 7 (2008).

2. Ehsani, M., Yimin Gao \& Gay, S. Characterization of electric motor drives for traction applications. in IECON'03. 29th Annual Conference of the IEEE Industrial Electronics Society (IEEE Cat. No.03CH37468) 891-896 (IEEE, 2003). doi:10.1109/IECON.2003.1280101.

3. Zeraoulia, M., Benbouzid, M. E. H. \& Diallo, D. Electric Motor Drive Selection Issues for HEV Propulsion Systems: A Comparative Study. IEEE Trans. Veh. Technol. 55, 1756-1764 (2006).

4. Li, G., Hong, W., Zhang, D., Zong, C., Research on Control Strategy of Two Independent Rear Wheels Drive Electric Vehicle. Physics Procedia, International Conference on Applied Physics and Industrial Engineering 2012 24, 87-93. https://doi.org/10.1016/j.phpro.2012.02.0141 (2012).

5. Renjith, S., Srinivasa, V. K. \& Shome, B. CFD based Prediction of Spin Power Loss of Automotive Differential System. SAE Int. J. Commer. Veh. 8, 460-466 (2015).

6. Eldho Aliasand, A., Josh, F.T., Selection of Motor foran Electric Vehicle: A Review. Materials Today: Proceedings, International Multi-conference on Computing, Communication, Electrical \& Nanotechnology, I2CN-2K19, 25th \& 26th April 2019 24, 18041815. https://doi.org/10.1016/j.matpr.2020.03.605 (2020).

7. Perez-Pinal, F. J., Nunez, C. \& Alvarez, R. Multi-motor synchronization technique applied in traction devices. in IEEE International Conference on Electric Machines and Drives,
$2005 . \quad 1542-1548 \quad$ (IEEE,

doi:10.1109/IEMDC.2005.195925.

2005).

8. Athari, A., Fallah, S., Li, B., Khajepour, A., Chen, S.-K., Litkouhi, B. Optimal Torque Control for an Electric-Drive Vehicle with InWheel Motors: Implementation and Experiments. (SAE 2013) Int. J. Commer. Veh. 6, 82-92. https://doi.org/10.4271/201301-0674

9. Haddoun, A. et al. Modeling, Analysis, and Neural Network Control of an EV Electrical Differential. IEEE Trans. Ind. Electron. 55, 2286-2294 (2008).

10. Sun, X., Hu, C., Zhu, J., Wang, S., Zhou, W., Yang, Z., Lei, G., Li, K., Zhu, B., Guo, Y., MPTC for PMSMs of EVs With MultiMotor Driven System Considering Optimal Energy Allocation.( IEEE Trans. Magn 2019). 55, 1-6. https://doi.org/10.1109/TMAG.2019.2904289

11. Cajander, D. \& Le-Huy, H. Design and optimization of a torque controller for a switched reluctance motor drive for electric vehicles by simulation. Mathematics and Computers in Simulation 71, 333-344 (2006).

12. Chan, C. C. et al. Novel permanent magnet motor drives for electric vehicles. IEEE Trans. Ind. Electron. 43, 331-339 (1996)

13. Ehsani, M., Gao, Y. \& Miller, J. M. Hybrid Electric Vehicles: Architecture and Motor Drives. Proc. IEEE 95, 719-728 (2007)

14. de Santiago, J. et al. Electrical Motor Drivelines in Commercial All-Electric Vehicles: A Review. IEEE Trans. Veh. Technol. 61 475-484 (2012).

15. Tahami, F., Kazemi, R. \& Farhanghi, S. A novel driver assist stability system for all-wheel-drive electric vehicles. IEEE Trans. Veh. Technol. 52, 683-692 (2003).

16. Fu, C., Hoseinnezhad, R., Watkins, S. \& Jazar, R. Direct Torque Control for Electronic Differential in an Electric Racing Car. in Sustainable Automotive Technologies 2012 (eds. Subic, A., Wellnitz, J., Leary, M. \& Koopmans, L.) 177-183 (Springer Berlin Heidelberg, 2012). doi:10.1007/978-3-642-24145-1_23.

17. Almeida, S. \& Araujo, R. E. Fault-tolerant control using sliding mode techniques applied to multi-motor electric vehicle. in IECON 2013 - 39th Annual Conference of the IEEE Industrial Electronics Society 3530-3535 (IEEE, 2013). doi:10.1109/IECON.2013.6699696.

18. Rahman, K. M. \& Ehsani, M. Performance analysis of electric motor drives for electric and hybrid electric vehicle applications. in Power Electronics in Transportation 49-56 (IEEE, 1996). doi:10.1109/PET.1996.565909.

19. Beniwal, J. L. \& Tripathi, R. K. Speed control of SRM drives using a new power converter configuration in electric vehicles. in 2014 Australasian Universities Power Engineering Conference (AUPEC) 1-6 (IEEE, 2014). doi:10.1109/AUPEC.2014.6966624.

20. Model and gear shifting control of a novel two-speed transmission for battery electric vehicles,. (Mechanism and Machine Theory 2020. ) 103902.https://doi.org/10.1016/j.mechmachtheory.2020 103902

21. de Castro, R., Araujo, R. E. \& Oliveira, H. Control in Multi-Motor Electric Vehicle with a FPGA platform. in 2009 IEEE International Symposium on Industrial Embedded Systems 219-227 (IEEE, 2009). doi:10.1109/SIES.2009.5196218.

22. Peng, H., Qin, D., Hu, J., Fu, C., Synthesis and analysis method for powertrain configuration of single motor hybrid electric vehicle.( Mechanism and Machine Theory 146 2020.), 103731 https://doi.org/10.1016/j.mechmachtheory.2019.103731

23. Gay, S.E., Hongwei Gao, Ehsani, M. Fuel cell hybrid drive train configurations and motor drive selection, in: Proceedings IEEE 56th Vehicular Technology Conference. Presented at the 2002 IEEE 56th Vehicular Technology Conference, (IEEE, 2002) Vancouver, BC, Canada, pp. 1007-1010. https://doi.org/10.1109/VETECF.2002.1040754 
24. Jinyun Gan, Chau, K. T., Chan, C. C. \& Jiang, J. Z. A new surface-inset, permanent-magnet, brushless DC motor drive for electric vehicles. IEEE Trans. Magn. 36, 3810-3818 (2000).

25. Kelecy, P. M. \& Lorenz, R. D. Control methodology for single inverter, parallel connected dual induction motor drives for electric vehicles. in Proceedings of 1994 Power Electronics Specialist Conference - PESC'94 987-991 (IEEE, 1994). doi:10.1109/PESC.1994.373800.

26. Kim, J. Optimal power distribution of front and rear motors for minimizing energy consumption of 4-wheel-drive electric vehicles. Int.J Automot. Technol. 17, 319-326 (2016).

27. Miller, J. M., Gale, A. R., McCleer, P. J., Leonardi, F. \& Lang, J. $H$. Starter-alternator for hybrid electric vehicle: comparison of induction and variable reluctance machines and drives. in Conference Record of 1998 IEEE Industry Applications Conference. Thirty-Third IAS Annual Meeting (Cat. No.98CH36242) vol. 1 513-523 (IEEE, 1998).

28. Murata, S. Innovation by in-wheel-motor drive unit. Vehicle System Dynamics 50, 807-830 (2012).

29. Mutoh, N., Kazama, T. \& Takita, K. Driving characteristics of an electric vehicle system with independently driven front and rear wheels. IEEE Trans. Ind. Electron. 53, 803-813 (2006).

30. Xiao, Z., Cao, J. \& Yu, Y. Mathematical Modeling and Dynamic Analysis of Planetary Gears System with Time-Varying Parameters. Mathematical Problems in Engineering 2020, 1-9 (2020).

31. Rahman, K. M. et al. Application of Direct-Drive Wheel Motor for Fuel Cell Electric and Hybrid Electric Vehicle Propulsion System. IEEE Trans. on Ind. Applicat. 42, 1185-1192 (2006).

32. Sakai, S., Sado, H. \& Hori, Y. Motion control in an electric vehicle with four independently driven in-wheel motors. IEEE/ASME Trans. Mechatron. 4, 9-16 (1999).

33. Sarigiannidis, A. G., Beniakar, M. E. \& Kladas, A. G. Fast Adaptive Evolutionary PM Traction Motor Optimization Based on Electric Vehicle Drive Cycle. IEEE Trans. Veh. Technol. 66, 5762-5774 (2017).

34. Weiss, M., Dekker, P., Moro, A., Scholz, H. \& Patel, M. K. On the electrification of road transportation - A review of the environmental, economic, and social performance of electric two-wheelers. Transportation Research Part D: Transport and Environment 41, 348-366 (2015).

35. West, J. G. W. DC, induction, reluctance and PM motors for electric vehicles. Power Engineering Journal 8, 77-88 (1994).

36. Zhang, H., Wang, C., Zhang, Y., Liang, J. \& Yin, C. Drivability improvements for a single-motor parallel hybrid electric vehicle using robust controls. J. Zheijang Univ.-Sci. 15, 291-301 (2014).

37. McFadden, P. D. A technique for calculating the time domain averages of the vibration of the individual planet gears and the sun gear in an epicyclic gearbox. Journal of Sound and Vibration 144, 163-172 (1991).

38. Richardson, D. B. Electric vehicles and the electric grid: A review of modeling approaches, Impacts, and renewable energy integration. Renewable and Sustainable Energy Reviews 19, 247-254 (2013).

39. De Carlo, M., Mantriota, G., Electric vehicles with two motors combined via planetary gear train. (Mechanism and Machine Theory 148, 2020.2$) 103789$. https://doi.org/10.1016/j.mechmachtheory.2020.103789

40. Hybrid dynamic modeling and analysis of the electric vehicle planetary gear system,. ( Mechanism and Machine Theory 150, 2020)

103860 . https://doi.org/10.1016/j.mechmachtheory.2020.103860

41. Amine, S., Mokhiamar, O.,. A study of stability and power consumption of electric vehicles using different modern control strategies. (Alexandria Engineering Journal 58, 2019) 12811290. https://doi.org/10.1016/j.aej.2019.10.010

42. Cao, J.-T., Liu, H.-H., Li, P., Brown, D.J., Dimirovski, G.,. A study of electric vehicle suspension control system based on an improved half-vehicle model. ( Int J Automat Comput 4, 2007) 236-242. https://doi.org/10.1007/s11633-007-0236-8

43. Chen, W., Liang, X., Wang, Q., Zhao, L., Wang, X., Extension coordinated control of four wheel independent drive electric vehicles by AFS and DYC. Control Engineering Practice 101, 104504. https://doi.org/10.1016/j.conengprac.2020.104504 (2020)

44. De Carlo, M., Mantriota, G., Electric vehicles with two motors combined via planetary gear train. (Mechanism and Machine Theory 148, $2020 . \quad 103789$. https://doi.org/10.1016/j.mechmachtheory.2020.103789

45. Dong, H., Fu, J., Zhao, Z., Liu, Q., Li, Y., Liu, J., A comparative study on the energy flow of a conventional gasoline-powered vehicle and a new dual clutch parallel-series plug-in hybrid electric vehicle under NEDC. (Energy Conversion and Management 218, 2020.) 113019 . https://doi.org/10.1016/j.enconman.2020.113019

46. Budală, A., Soica, A., An Experimental Research on Power Losses into an Automotive Manual Transmission. pp. 527-534. https://doi.org/10.1007/978-3-319-94409-8_61 (2019).

47. Eckert, M., Gauterin, F. Efficiency Optimised Vehicle Dynamics Control in Electric Vehicles with Wheel-Individual Drives. (ATZ Elektron Worldw 8, 2013) 50-57. https://doi.org/10.1365/s38314-013-0200-z

48. Peng, D., Smith, W.A., Borghesani, P., Randall, R.B., Peng, Z., Comprehensive planet gear diagnostics: Use of transmission error and mesh phasing to distinguish localised fault types and identify faulty gears. ( Mechanical Systems and Signal Processing 127, 2019) 531-550. https://doi.org/10.1016/j.ymssp.2019.03.024

49. Rahman, K.M., Ehsani, M., Performance analysis of electric motor drives for electric and hybrid electric vehicle applications, in: Power Electronics in Transportation. (Presented at the Power Electronics in Transportation, 1996. ) pp. 49-56. https://doi.org/10.1109/PET.1996.565909 


\section{Supplementary Files}

This is a list of supplementary files associated with this preprint. Click to download.

- suplimentrymaterial.doc 